Cite this: Metallomics, 2014, 6,444

Received 24th October 2013, Accepted 28th November 2013

DOI: $10.1039 / c 3 m t 00317 e$

www.rsc.org/metallomics

\title{
A different sequence of events than previously reported leads to arsenic-induced damage in Ceratophyllum demersum L. $\dagger$
}

\author{
Seema Mishra, ${ }^{a b}$ Hans-Joachim Stärk ${ }^{b}$ and Hendrik Küpper*ac
}

\begin{abstract}
Arsenic (As) is a common pollutant, and still many questions remain concerning As toxicity mechanisms under environmentally relevant conditions in plants. Here we investigated thresholds and interactions of various proposed As toxicity mechanisms. Experiments were done under environmentally pertinent conditions in the rootless aquatic macrophyte Ceratophyllum demersum L., a model for plant shoots. Arsenic (provided as As(v)) inhibited plant metabolism at much lower concentrations and with a different sequence of events than previously reported. The first observed effect of toxicity was a decrease in pigment concentration, it started even at $0.5 \mu \mathrm{M}$ As. In contrast to toxic metals, no inhibition of the photosystem II reaction centre (PSIIRC; measured as $F_{\mathrm{v}} / F_{\mathrm{m}}$ ) was found at sublethal As concentrations. Instead, the decrease in light harvesting pigments caused a less efficient exciton transfer towards the PSIIRC. At higher As concentrations this led to increased non-photochemical quenching (NPQ) by light harvesting complex ॥ (LHCII). Afterwards, photosynthetic electron transport decreased, but the increase in starch content indicated stronger inhibition of starch consumption than production. At lethal As concentration, photosynthesis was completely inhibited, its malfunction caused oxidative stress and not the other way round as reported previously. Photosynthesis was inhibited before any sign of oxidative stress was observed. Elevated phosphate drastically shifted thresholds of lethal As effects, not only by the known uptake competition but also by modifying uptake regulation and intracellular processes.
\end{abstract}

\section{Introduction}

Toxic levels of arsenic (As) in soil and drinking water have been reported around the world, with the worst situations in South and South-east Asia. ${ }^{1-4}$ Arsenic concentrations $>50 \mu \mathrm{g} \mathrm{L}^{-1}(0.67 \mu \mathrm{M})$ are common in India and Bangladesh, and concentrations exceeding even $2000 \mu \mathrm{g} \mathrm{\textrm {L } ^ { - 1 }}(27 \mu \mathrm{M})$ have been reported. ${ }^{1,5}$ Arsenic induced yield loss has recently been recognized as a threat to the sustainability of food production. ${ }^{3}$ To counter the detrimental impacts of As, phytoremediation or the development of crops that can be grown in contaminated environments

\footnotetext{
${ }^{a}$ University of Konstanz, Department of Biology, Postbox M631, D-78457 Konstanz, Germany. E-mail: hendrik.kuepper@uni-konstanz.de, seema_mishra2003@yahoo.co.in; Tel: +49-7531-884112

${ }^{b}$ Helmholtz Centre for Environmental Research-UFZ, Department of Analytical Chemistry, Permoserstr. 15, D-04318 Leipzig, Germany

${ }^{c}$ University of South Bohemia, Faculty of Biological Sciences and Institute of Physical Biology, Branišovská 31, CZ-370 05 České Budejovice, Czech Republic

$\dagger$ Electronic supplementary information (ESI) available: Composition of the nutrient solution and explanations of fluorescence kinetic parameters (Table S1 and S2); figures of pigments and photosynthetic parameters (Fig. S1 and S2), methodology of gas exchange and starch and figures of photosynthesis and respiration (Fig. S3). Line graph versions showing error bars of all 2Dcolourmap figures (Fig. S4-S9). See DOI: 10.1039/c3mt00317e
}

without suffering from and accumulating As in edible parts seems to be the most appropriate strategy. Both the strategies demand understanding the mechanistic details of As uptake, toxicity and detoxification. ${ }^{5}$

Arsenic is taken up by plants mainly as inorganic arsenate $\left[\mathrm{HAsO}_{4}{ }^{2-}\right.$ or $\left.\mathrm{As}(\mathrm{v})\right]$ and arsenite $\left[\mathrm{H}_{2} \mathrm{AsO}_{3}{ }^{-}\right.$or $\left.\mathrm{As}(\mathrm{III})\right]$ through high-affinity phosphate transporters ${ }^{6}$ and by nodulin26-like intrinsic (NIPs) aquaporins ${ }^{7,8}$ respectively. Inside the cell, As(v) can interfere with metabolic processes such as oxidative phosphorylation and ATP synthesis or, after reduction to As(III), through interaction with thiol groups of proteins. ${ }^{9}$ To combat the As stress, plants modulate a number of pathways from subcellular compartmentalization to biochemical tolerance through antioxidantmediated ROS quenching. ${ }^{10-13}$

However, the mechanisms of As toxicity, though well known in animals, including humans, ${ }^{14}$ are not fully understood in plants under environmentally relevant conditions. Studies have shown that As toxicity leads to reduced germination, inhibited root and shoot growth and biomass production, reduced chlorophylls and grain yield, ultimately leading to death. ${ }^{13,15,16}$ Arsenic exposure has been shown to induce generation of reactive oxygen species (ROS). ${ }^{12,13,17,18}$ This could be caused by the redox activity of $\mathrm{As}^{19}$ and could lead to lipid peroxidation and associated toxicity. ${ }^{20}$ 
However, most of the studies on plants have been done on As hyperaccumulators or tolerant plants, which can withstand higher levels of As through specific mechanisms.9,11,21 Some studies concerning As toxicity in non-tolerant plants have been done as well, ${ }^{16,20,22-24}$ but they were mostly performed with short-term exposure (few hours or days) to high As concentrations (hundred micromolar to millimolar). Experiments with such high concentrations for plants that are not specifically As-tolerant do not adequately simulate As toxicity in the environment, where the level of As in water or in soil solution would almost never become so high. For example, Wenzel et $a .^{25}$ reported from $\leq 53 \mathrm{nM}$ to $2.3 \mu \mathrm{M} \mathrm{As}(\mathrm{v})$, from a range of uncontaminated to highly contaminated soils and Abedin et $a .^{26}$ reported $4.3 \mu \mathrm{M}$ total As in soil solution upon irrigation with $106 \mu \mathrm{M}$ As containing water. Further, a plant in its natural environment has to survive for much longer periods to produce adequate biomass for phytoremediation or grain yield.

The aim of the present study was to analyze As stress mechanisms in a holistic manner under environmentally relevant conditions i.e. of light, temperature, nutrient supply and As concentrations, in order to establish a mechanism of As toxicity, which can give insight into the plants' response to chronic As exposure in the natural environment. For this purpose, a detailed investigation of photosynthesis biophysics, pigment contents, gas exchange, ROS generation and nutrient uptake was done on Ceratophyllum demersum. This widespread submerged macrophyte (occurring in Asia, Europe and North America) has no roots such that it takes up all nutrients directly via the leaves, making studies of shoot effects possible without interference from root uptake and root toxicity. Although it is not a crop species, it is still a flowering plant (belonging to the dicotyledons) and has been accepted as a good model for laboratory studies of shoot toxicity in higher plants. ${ }^{27}$ Mechanisms of metal toxicity found in Ceratophyllum are similar to other plants and like other non-accumulator plants including crops it detoxifies arsenic by phytochelatins. ${ }^{12,28}$ It has been shown to be effective for removing the metal from low-concentration wastewater and has also been used successfully in tests of biological life support systems on space flights. ${ }^{29}$

\section{Material and methods}

\section{Plant material and cultivation}

Ceratophyllum demersum L. plants were grown in hydroponic nutrient solution optimized for submerged macrophytes (SMNS, personal communication, final concentrations are listed in Table S1, ESI $\dagger$ ). The solution was aerated continuously and constantly exchanged at a rate of $0.4 \mathrm{~mL} \mathrm{~min}^{-1}$, with $2 \mathrm{~L}$ resident volume. Plants were grown under the following conditions: $14 \mathrm{~h}$ day length, $24{ }^{\circ} \mathrm{C}$ day, $20{ }^{\circ} \mathrm{C}$ night temperature and a sinusoidal light cycle with a maximum of $100 \mu \mathrm{mol} \mathrm{m} \mathrm{m}^{-2} \mathrm{~s}^{-1}$ at noon, supplied by “daylight” fluorescent tubes (Dulux L 55 W/12-950, Osram, München, Germany).

For the experiments, plants of similar weight (approximately $1 \mathrm{~g}$ each) were chosen from stock culture and exposed to various concentrations of $\mathrm{As}(\mathrm{v})(0,0.5,1,2,5,10$, and $20 \mu \mathrm{M}$ prepared by $\mathrm{Na}_{2} \mathrm{HAsO}_{4}$; Alfa Aesar, Ward Hill, MA, USA) in nutrient solution for four weeks. Each aquarium contained one plant. Two concentrations of phosphate were used: $10 \mu \mathrm{M}$ phosphate = "high $\mathrm{P}$ " and $1 \mu \mathrm{M}$ phosphate $=$ "low $\mathrm{P}$ ". To minimize variations in the biomass/media ratio over the course of the experiment, after the weekly determination of fresh weight, the plants were cut to the fresh weight of the plant having the lowest growth rate, unless their biomass decreased. Measurements of physiological parameters were carried out at the beginning, every week and/or after harvest. Harvested plants were washed in As-free nutrient solution and shaken to remove surface water. The plant part $4 \mathrm{~cm}$ from the tip and side branches were sampled as young tissue, and the remaining parts were sampled as old tissue. The samples were frozen immediately in liquid nitrogen and stored at $-80{ }^{\circ} \mathrm{C}$ until further analysis.

\section{Growth measurement and visual toxicity}

Plants were photographed every week, and morphological changes were observed. The growth rate of each plant was calculated by measuring the fresh weights every week. For weight measurement, plants were shaken gently to remove surface water. The growth of plants in terms of new whorls of leaves appearing per week on the main stem was monitored.

\section{Elemental analyses}

Frozen plant material (5-15 mg) was lyophilized and digested as described by Zhao et al. ${ }^{30}$ The volume was made up to $1.5 \mathrm{~mL}$ with $\mathrm{ddH}_{2} \mathrm{O}$, and element concentrations were analysed using a sector field inductively coupled plasma mass spectrometer (ICP-MS; Element XR, Thermo Fisher Scientific, Waltham, MA, USA). Prior to analysis, ICP-MS parameters were optimized every day, and samples were diluted to $1: 20$. The calibration was verified using the following reference materials: SLRS-5 (River Water Reference Material for Trace Metals, NRCC), SPSSW1 (Surface Water Level 1, Spectra Pure Standards) and SRM 1643e (Trace Elements in Water, NIST). Rhodium $\left(4 \mu \mathrm{g} \mathrm{L}^{-1}\right)$ was added to all samples for internal standardization.

\section{Determination of pigment content}

Lyophilized plant material was ground to a fine powder, and pigments were extracted in $100 \%$ acetone $v s$. acetone over night at $4{ }^{\circ} \mathrm{C}$ in dark. Spectra of crude pigment extracts were measured using the UV/VIS spectrophotometer Lambda 750 (Perkin-Elmer, Germany) at a spectral bandwidth of $1 \mathrm{~nm}$ with a $0.2 \mathrm{~nm}$ sampling interval from 350 to $750 \mathrm{~nm}$. Pigments were quantified according to the "Gauss-peak-spectra" (GPS) method by Küpper et $a l .{ }^{31}$ with an updated pigment database.

\section{Chlorophyll fluorescence kinetic microscopy (FKM)}

Arsenic-induced changes in photosynthetic light reactions were analysed by two dimensional (imaging) microscopic measurements using the Fluorescence Kinetic Microscope ${ }^{32}$ (FKM). One leaf from the 4 th whorl counted from the tip of the plant was cut off and fixed in the measuring chamber using 
gas-permeable cellophane. The culture medium without micronutrients, maintained at $25{ }^{\circ} \mathrm{C}$, was continuously flowing through the measuring chamber as described in Andresen et al. ${ }^{33}$ The leaf area just before the branching (approximate size of $1.1 \times 1.1 \mathrm{~mm}$ ) was focused for both spatially and spectrally resolved kinetics measurements. The measurement protocol and data analysis method was applied according to Küpper et al. ${ }^{32}$ All fluorescence kinetic parameters used in the current work are explained in Table S2, ESI. $\dagger$

\section{Determination of superoxide production}

Superoxide production was determined by using a superoxide specific chemoluminescent dye, a methyl cypridina luciferin analogue (MCLA; 2-methyl-6-(p-methoxyphenyl)-3,7-dihydroimidazol[1,2-alpha]pyrazin-3-1 hydrochlorohydrate; Life Technologies, Darmstadt, Germany) following Rocchetta and Küpper $^{34}$ with slight modifications. Two leaves from the 4 th whorl counted from the tip of the plant were placed in cuvettes containing $2 \mathrm{~mL}$ of nutrient solution without micronutrients and immediately exposed to $25 \mu \mathrm{mol} \mathrm{m}{ }^{-2} \mathrm{~s}^{-1}$ light. After $30 \mathrm{~min}$, the leaves were taken out, dye was added to a final concentration of $0.05 \mu \mathrm{M}$, and chemoluminescence was measured for $10 \mathrm{~min}$. A sample without leaves was prepared and measured in the same way for correcting dye luminescence. Data were recorded using a LKB 1250 luminometer connected to the OxyCorder used for gas exchange measurement and analysed using Microcal Origin Professional 8.6 (see ESI $\dagger$ ).

\section{Determination of peroxide production}

$\mathrm{H}_{2}$ DCFDA dye (5-(and 6-)-carboxy-2' , $^{\prime}$-dichlorodihydrofluorescein diacetate; Life Technologies, Darmstadt, Germany) was used for measuring hydrogen peroxide and related oxidative species in the tissues, following the method described by Rocchetta and Küpper $^{34}$ with slight modifications. The dye, $0.2 \mu \mathrm{M}$ final concentration, was diluted from $100 \mu \mathrm{M}$ stock in $1 \mathrm{~mL}$ of nutrient solution in a microcentrifuge tube, and two leaves from the 4th whorl of the plant were incubated in this tube for $30 \mathrm{~min}$ in the dark. After cleavage of the acetate groups by intracellular esterases, the oxidation of the dye by peroxide fluorescence was measured in the FKM using filter set F41-028 (HQ-YFP) from AHF (Tübingen, Germany) with excitation at $490-510 \mathrm{~nm}$, a $515 \mathrm{~nm}$ dichroic mirror and a 520-550 $\mathrm{nm}$ emission filter.

\section{Statistics}

Unless stated otherwise, two-way analysis of variance (ANOVA) was done using SigmaPlot 11 (SPSS Science, USA) at a significance level of $P=0.05$. In ANOVA, " $n$ " is the number of independent data points entered into the analysis. For $x$ independent experiments with $y$ treatments and $z$ different tissue types, for example, it is $x \times y \times z$. For significant effects, a post-hoc all-pairwise comparison via the Holm-Sidak method was performed. Correlations between parameters were tested via regressions using the most appropriate model in Microcal Origin Professional 8.6 (Originlab, Northampton, USA).

\section{Results}

Note: though As was provided as As(v), it is known that it becomes partially reduced to As(III) in plants and also in solution due to efflux from plants. ${ }^{27,35}$ Therefore, in the following we only use the label "As" for this mixture of redox states. Since all figures (except Fig. 1b) are made on a log scale, the control (" $0 \mu \mathrm{M}$ " As) treatment is labeled as " $0.1 \mu \mathrm{M}$ As" in these figures. While the two-dimensional features (the dependence on both As concentration and time) can only be seen in the truly two-dimensional graphs (i.e. having both a time axis and a concentration axis) shown in the main manuscript, we added line graph versions of these data to the ESI $\dagger$ (Fig. S4-S9) for showing error bars that cannot be shown in 2D-graphs.

\section{Growth of plants and visible symptoms of toxicity}

In the absence of As, the plants grew significantly better under low $\mathrm{P}$ conditions $(n=42, P<0.001)$. At high As, the growth was better under high $\mathrm{P}$ conditions, as discussed later (Fig. 1). Thus, the concentration of $\mathrm{P}$ was not limiting for the growth of plants under our "low P"' conditions.

After exposure to As under low $\mathrm{P}$ conditions, visible symptoms of toxicity started to appear from $2 \mu \mathrm{M}$ after one week with fewer growing side branches and stunted meristems. Meristems completely disappeared, and leaves were closed at $20 \mu \mathrm{M}$ As after one week. The lowering of the growth rate in terms of fresh weight, however, already started from $0.5 \mu \mathrm{M}$ As after one week. The growth rate became negative, i.e. the loss of leaves at the lower end of plants was higher than the development of new leaves at the tip, from $2 \mu \mathrm{M}$ As after four weeks and from $10 \mu \mathrm{M}$ after one week. The number of new whorls of leaves appearing per week on the main stem started to decline from $5 \mu \mathrm{M}$ and reached $50 \%$ at $20 \mu \mathrm{M}$ after one week and at $5 \mu \mathrm{M}$ after four weeks. Thus beyond $5 \mu \mathrm{M}$ As, there were no young tissues available for analysis of parameters done after harvest (analysis of elements and starch which needed mg quantities of tissue). As such, $5 \mu \mathrm{M}$ As was the threshold concentration for lethal effects.

At high $\mathrm{P}$, the decrease in growth was less than at low $\mathrm{P}$. The maximum decrease in growth was observed after two weeks, where retardation in growth started with $2 \mu \mathrm{M}$ As and reached a maximum at $20 \mu \mathrm{M}$ As $(n=42, P<0.001)$. However, beyond two weeks, the plants recovered at sublethal concentrations, mostly at 2 and $5 \mu \mathrm{M}$ As. Visible symptoms of toxicity, i.e. stunted meristems and disassembling of leaves started to appear only at $20 \mu \mathrm{M}$ As after two weeks. After four weeks of $20 \mu \mathrm{M}$ As treatment, the appearance of new whorls of leaves decreased by $40 \%$ in comparison to control.

\section{Effect of As on accumulation of phosphorus and sulphur}

Under low P conditions, a strong accumulation of As was observed in both young and old parts of the plant, with a slightly higher accumulation of As in young tissues than in old tissues. Under high $\mathrm{P}$ conditions, the accumulation of As was relatively gradual up to $20 \mu \mathrm{M}$ As exposure, and old tissues tended to accumulate more As at all exposure concentrations (Fig. 2). The accumulation of As was maximal at $5 \mu \mathrm{M}$ As at low $\mathrm{P}$, which was about 2.3 and 1.9 fold higher than the maximum accumulation at high 
$\mathrm{P}$ at $20 \mu \mathrm{M}$ As for young and old tissues, respectively. Under low $\mathrm{P}$ conditions beyond $5 \mu \mathrm{M}$ As exposure, the accumulation of As dropped drastically in old parts of the plant while no young tissues were available for analysis.

The level of S in plants was significantly positively correlated with As accumulation, both under low and high $\mathrm{P}$ conditions and young and old tissues of the plant (for high $\mathrm{P}$, linear fit on $\log$ (As) vs. $\log (\mathrm{S})$, young: $R_{2}=0.99$, old: $R_{2}=0.97$, and for low $\mathrm{P}$, linear fit on As vs. S, young: $R_{2}=0.99$, old: $R_{2}=0.98$ ) (Fig. 2). At low $\mathrm{P}$, the level of $\mathrm{S}$ increased up to the $5 \mu \mathrm{M}$ As treatment in both young and old tissues, which contained 183\% and 95\% higher $\mathrm{S}$ in comparison to control, respectively. At high $\mathrm{P}$, the level of $\mathrm{S}$ was about 67 and $90 \%$ higher at $20 \mu \mathrm{M}$ As in young and old tissues than the controls, respectively.

Accumulation of $\mathrm{P}$ in control plants reflected the external concentration of $\mathrm{P}$ in solution, i.e. the high $\mathrm{P}$ plants accumulated about $10 \times$ more $\mathrm{P}$ than plants grown with low $\mathrm{P}$ (Fig. 2). The level of $\mathrm{P}$ was significantly higher in young parts under both high and low P conditions (high P: $n=42$, low P: $n=20, P<0.001$ ) at all As exposures. There was a slight decrease in $\mathrm{P}$ accumulation upon As exposure in high $\mathrm{P}$ plants, while in low $\mathrm{P}$ plants a significant increase in $\mathrm{P}$ accumulation was observed from $2 \mu \mathrm{M}$ As exposure (high P: $n=42, P=0.102$, low P: $n=20, P<0.003$ ).

\section{Effect of As on pigment composition}

In control plants, pigment concentrations were significantly higher under low $\mathrm{P}$ conditions $(n=42, P<0.001)$ and at low $\mathrm{P}$, As had a greater effect on pigments than at high $\mathrm{P}$ (Fig. 3 and Fig. S1, ESI $\dagger$ ).

Under low $\mathrm{P}$ conditions, a concentration and duration dependent decrease in total Chl was observed upon exposure to As. At $20 \mu \mathrm{M}$ As after four weeks, young leaves contained approximately $86 \%$ less Chl compared to the control (Fig. 3a). (a)

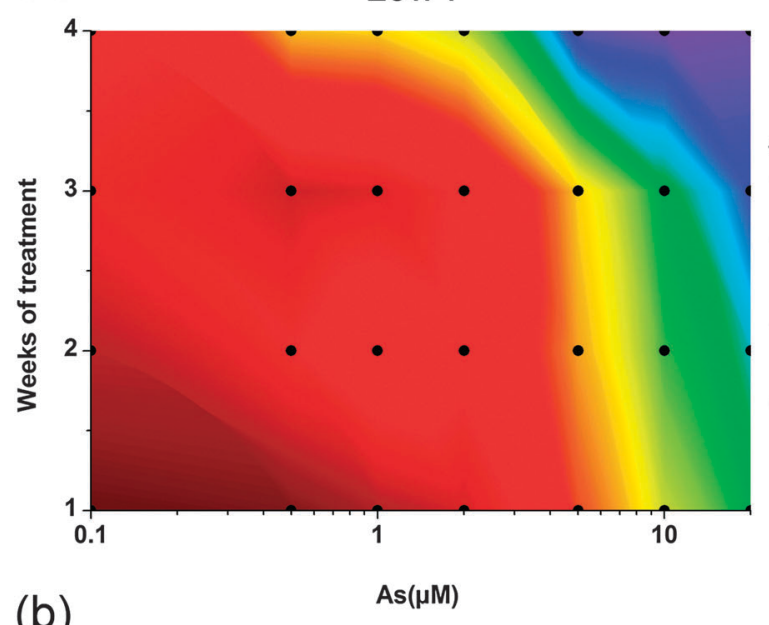

(b)

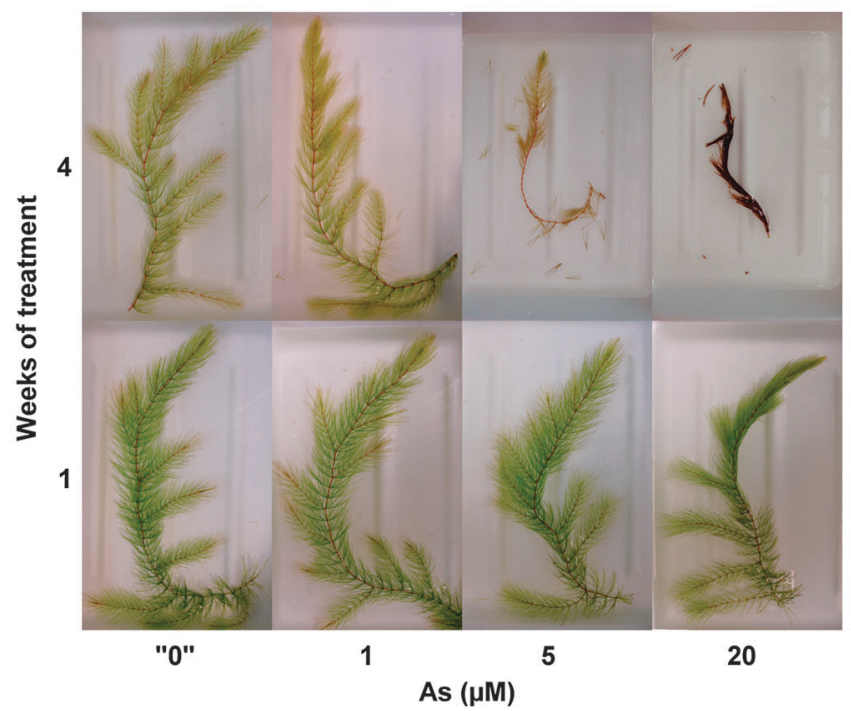

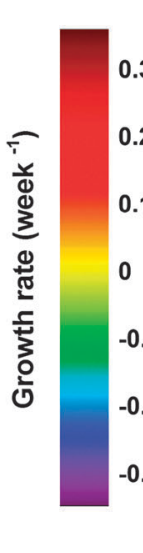

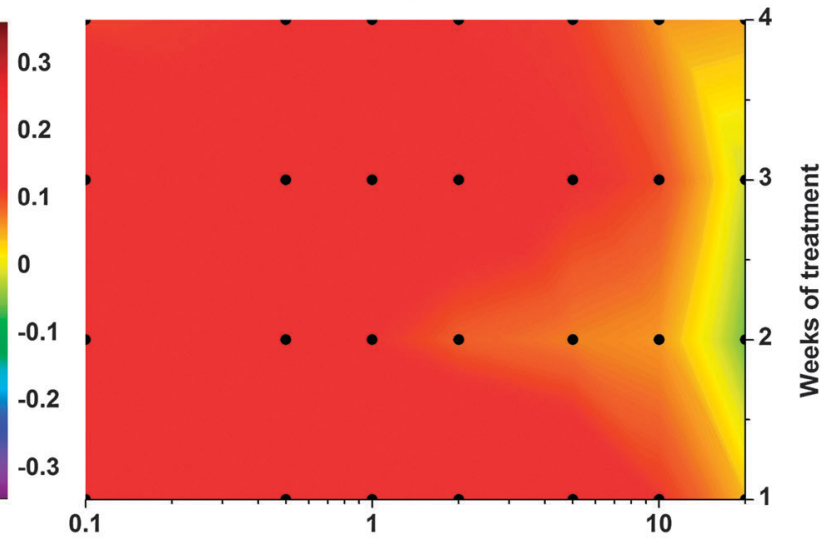

As $(\mu \mathrm{M})$

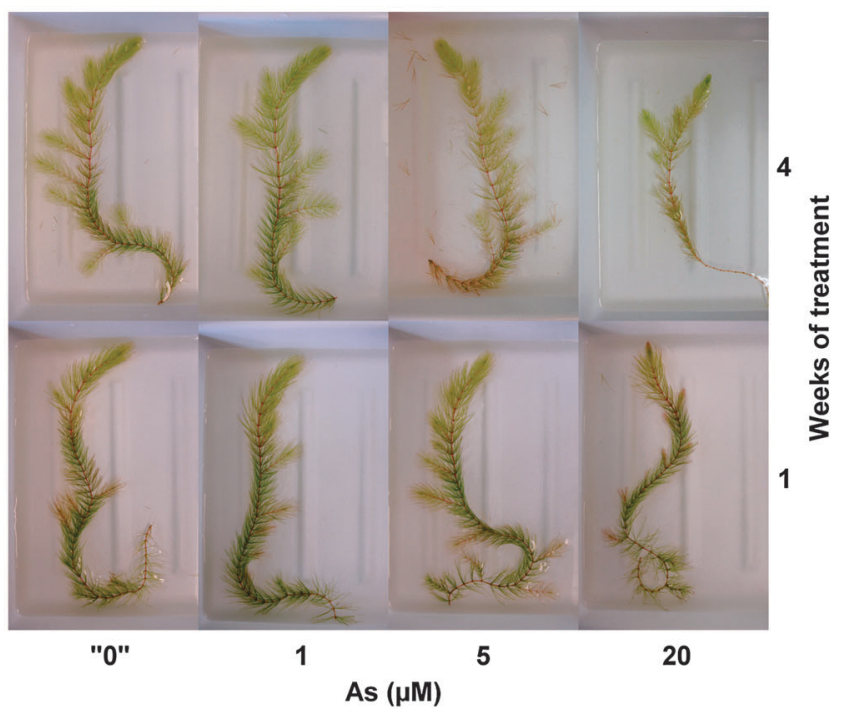

Fig. 1 Growth response of Ceratophyllum demersum exposed to As under low and high P conditions. (a) Growth rate of the plants per week calculated on the basis of fresh weight. Negative growth rates means a net loss of biomass i.e. more tissue dies off and decays from the lower part of the plant than what is growing new at the tip of the plant. The data are the mean of three experiments (two-dimensional figure showing the time course on the $Y$ and the As concentration series on the $X$ axis, with linear interpolation between measured points). (b) Visual symptoms of As toxicity. 


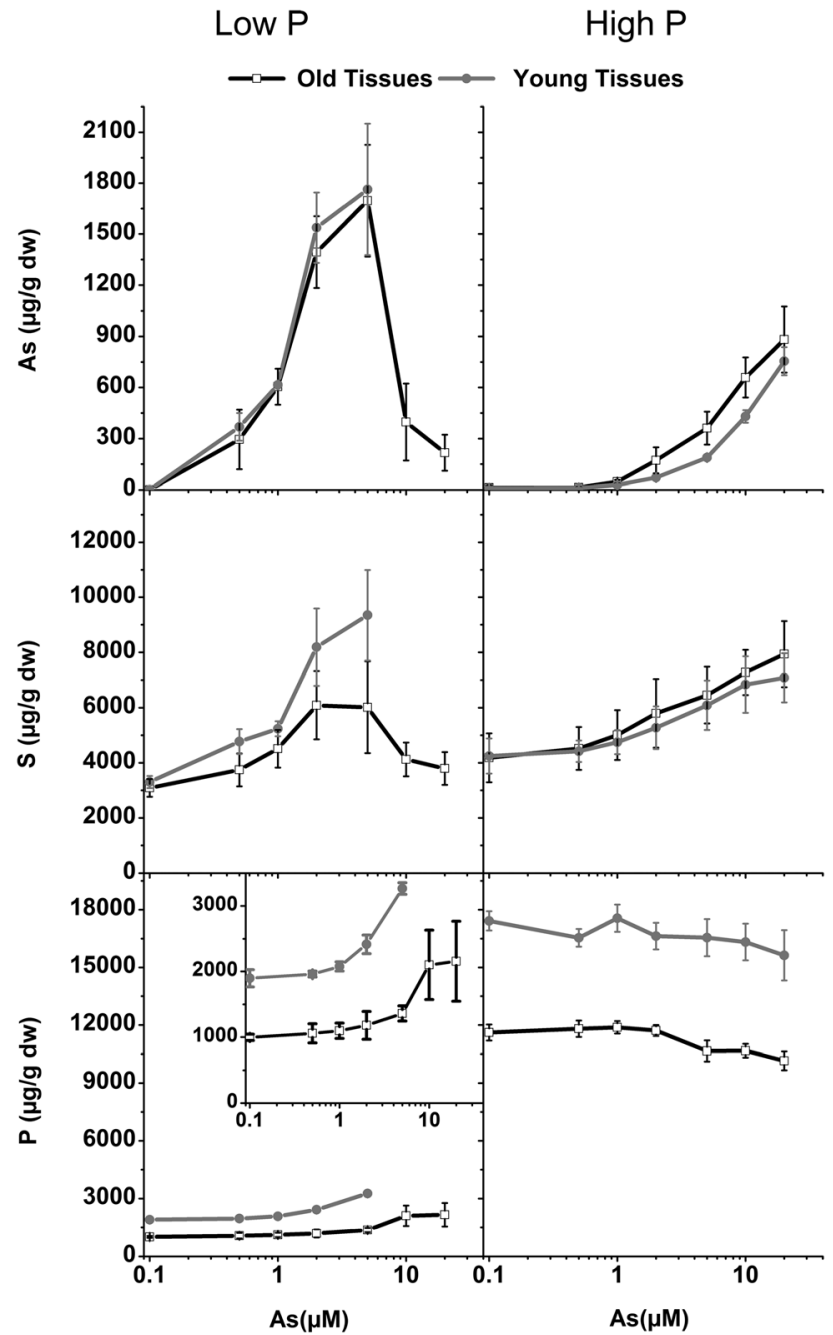

Fig. 2 Accumulation of As and other elements in young and old tissues. Plants were exposed to As under low and high P conditions for four weeks. Data are mean $\pm \mathrm{SE}$ of three experiments.

Measurements done after harvest also showed a continuous decrease in Chl a and Chl b in both young and old tissues, except for a sudden increase in Chl a in old tissues at 10 and $20 \mu \mathrm{M}$ As (Fig. S1b, ESI $\dagger$ ). At high $\mathrm{P}$, the maximum effect on total Chl occurred after two weeks, with about $45 \%$ decrease in total Chl observed at $2 \mu \mathrm{M}$ As and a maximum amount of a $49 \%$ decrease at $20 \mu \mathrm{M}$ As in comparison to control (Fig. 3a). Beyond two weeks, no further decrease in total $\mathrm{Chl}$ content occurred. At high $\mathrm{P}$, measurements done after harvest showed that in old tissues, decrease in Chl a and Chl b started only from $5 \mu \mathrm{M}$ As while in young tissues it started even at $0.5 \mu \mathrm{M}$ As (Fig. 3 and Fig. S1b, ESI $\dagger$ ).

Due to almost identical UV absorption spectra, antheraxanthin and lutein, as well as $\beta$-carotene and zeaxanthin, could not be distinguished from each other and therefore were quantified together and termed 'antheraxanthin + lutein' and ' $\beta$-carotenelike pigments' ${ }^{31}$ The time course measurement showed that at low $\mathrm{P}$, the level of antheraxanthin + lutein decreased drastically at $>1 \mu \mathrm{M}$ As after one week and reached almost zero after three weeks at lethal As $(n=105, P<0.001)$. At high $\mathrm{P}$, the level of
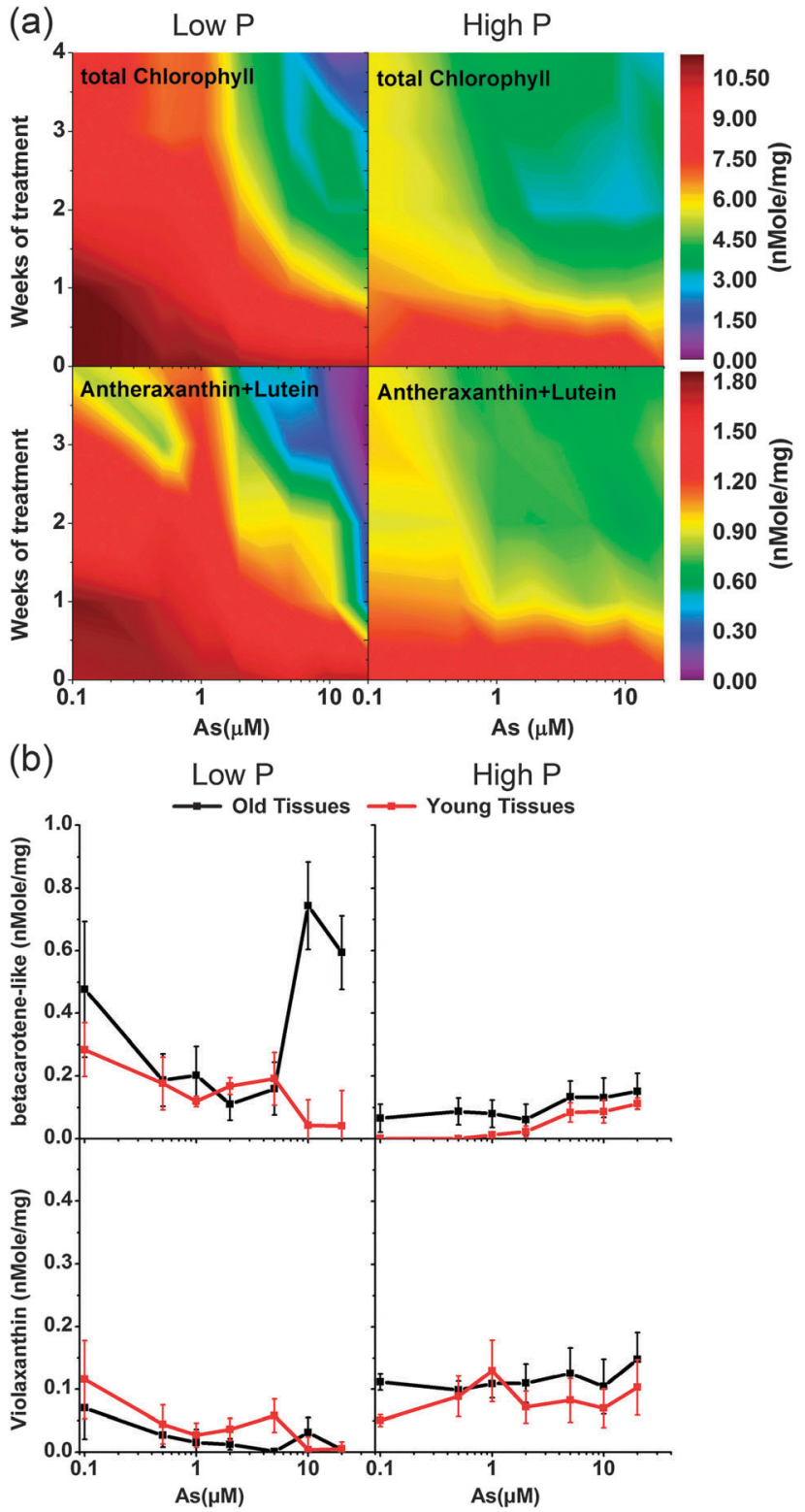

Fig. 3 Effect of As on photosynthetic pigments under low and high $\mathrm{P}$ conditions. (a) Effect on total chlorophyll and antheraxanthin + lutein during four weeks of As exposure (two-dimensional figure showing the time course on the vertical axis and the As concentration series on the horizontal axis of each panel). The data are the mean of three experiments. (b) Effect on $\beta$-carotene-like pigments and violaxanthin after four weeks in young and old tissues. Data are mean \pm SE of three experiments. Antheraxanthin and lutein and $\beta$-carotene and zeaxanthin could not be distinguished from each other due to almost identical UV absorption spectra. Thus, these were quantified together and termed 'antheraxanthin + lutein' and ' $\beta$-carotene like pigments'.

antheraxanthin + lutein decreased significantly $(n=105, P<0.001)$ in comparison to control, however it was significantly $(n=42$, $P<0.001$ ) higher than at low $\mathrm{P}$ (Fig. 3a). At low $\mathrm{P}$, the $\beta$-carotenelike pigments and violaxanthin mostly decreased (except for an increase in old leaves at lethal As), while at high $\mathrm{P}$ both $\beta$-carotene-like pigments and violaxanthin showed an increasing trend with a significant increase in comparison to control from 
$5 \mu \mathrm{M}$ in both young and old tissues $(n=42, P<0.001)$ (Fig. $3 \mathrm{~b}$ ). Only little change was observed in the Chls to carotenoid ratio at high $\mathrm{P}(n=42, P=0.057)$, but at low $\mathrm{P}$ it was significantly decreased with $20 \mu \mathrm{M}$ As in young tissues $(n=42, P<0.001)$ (Fig. S1b, ESI $\dagger$ ).

\section{Effect of As on photosynthesis}

To help readers outside the field of photosynthesis biophysics, all parameters of fluorescence kinetics discussed in the following. are explained in more detail in Table S1 (ESI $\dagger$ ) and the references mentioned there.

Under both high $\mathrm{P}$ and low $\mathrm{P}$ conditions, $F_{\mathrm{O}}$ (minimal darkadapted fluorescence yield) and $F_{\mathrm{m}}$ (maximum fluorescence yield in a dark adapted sample) followed the same trend as the respective total chlorophyll contents (Fig. S2, ESI $\dagger$ ).

Light-acclimated photochemical quenching $\left(\Phi_{\mathrm{PSII}}=\right.$ lightacclimated electron flow through PSII, $\Phi_{\text {PSII_i6 }}=200 \mathrm{~s}$ after start of actinic light $\$$ ) showed inhibition starting already after one week with $5 \mu \mathrm{M}$ As. The photochemical quenching $10 \mathrm{~s}$ after the start of actinic light ( $\Phi_{\text {PSII_i1) }}$ was inhibited after two weeks from $5 \mu \mathrm{M}$ As. The photosynthetic quantum efficiency of the PSII reaction centre (PSIIRC) in the dark adapted state (measured as $F_{\mathrm{v}} / F_{\mathrm{m}}$ ) started to decrease only after three weeks from $5 \mu \mathrm{M}$ As at low P (Fig. 4a left panel). The relaxation of photochemical quantum efficiency of PSII in the dark $\left(\Phi_{\text {PSII_r }}\right.$ = $200 \mathrm{~s}$ after switching off actinic light) showed no significant effect at $10 \mu \mathrm{M}$ As up to one week and at $2 \mu \mathrm{M}$ As up to four weeks ( $n=70, P=0.934)$. Beyond that it decreased concentrationand duration-dependently. At high $\mathrm{P}$, generally no significant effect on photochemical parameters was observed below $20 \mu \mathrm{M}$ As. Only $F_{\mathrm{v}} / F_{\mathrm{m}}$ slightly decreased at $20 \mu \mathrm{M}$ after four weeks ( $n=105, P=0.016$ ) (Fig. 4a right panel).

At low $\mathrm{P}$, the light saturation of PSII (measured as $\left(F_{\mathrm{p}}-F_{\mathrm{o}}\right) /$ $\left.\left(F_{\mathrm{m}}-F_{\mathrm{o}}\right)\right)$ decreased at higher As concentrations and/or duration of As treatment, reaching almost zero at $20 \mu \mathrm{M}$ from week three. In contrast, the saturation parameter increased upon As exposure in high P plants (Fig. S2, ESI $\dagger$ ).

At low $\mathrm{P}$, the non-photochemical quenching (NPQ, up-regulation of exciton dissipation as heat in response to actinic light, Fig. 4b) increased compared to the control at the beginning of exposure to low As (i.e. one week up to $10 \mu \mathrm{M}$ or four weeks up to $2 \mu \mathrm{M}$ ). Beyond that, i.e. at higher As or longer exposure, NPQ both at the beginning (NPQ_i1) and at the end (NPQ_i6) of the actinic light phase of the measuring protocol decreased compared to the control. The relaxation of non-photochemical quenching after $200 \mathrm{~s}$ of dark phase (NPQ_relax = (NPQ_i6-NPQ_r5)/ NPQ_i6) was higher compared to the control at lower As exposure i.e. at $1 \mu \mathrm{M}$ after two weeks and at $5 \mu \mathrm{M}$ after one week and then started to decline below control (Fig. 4b left panel). As a result of this declining NPQ relaxation, the NPQ remaining after switching off actinic light (10 s dark acclimation: NPQ_r1; 200 s dark acclimation: NPQ_r5) was much higher in sublethally As-stressed plants than in the control

\$ Indices i1, r6, r5; i1: after $10 \mathrm{~s}$ of actinic light; i6: after $200 \mathrm{~s}$ of actinic light; r5: after $200 \mathrm{~s}$ relaxation in the dark after the actinic light period.
(Fig. 4 and Fig. S2, ESI $\dagger$ ). At high P, the As effects on NPQ were far less pronounced than at low P. A significant decrease in NPQ in comparison to control occurred only at $20 \mu \mathrm{M}$ As after four weeks at the end of actinic light (NPQ_i6) $(n=105, P=0.003)$. The data for NPQ_r1 and NPQ_r5 were noisy for high P plants, but still some increase upon exposure to higher As concentrations and for longer duration was visible for NPQ_r5 (Fig. 4b right panel).

To get more detailed information about the changes of NPQ, spectrally resolved fluorescence kinetics were measured (Fig. 5). It showed a similar As-dependence and spectral pattern of NPQ in the presence of actinic light both after one and two weeks, with an initial increase at sublethal As that was more pronounced at shorter wavelengths. A decline of NPQ was observed at lethal As in low P plants. After one and two weeks of As exposure, the residual NPQ after $200 \mathrm{~s}$ dark relaxation (NPQ_r5) showed a sharp peak at 2 to $5 \mu \mathrm{M}$ As, with maximum NPQ at shorter wavelengths (Fig. 5). At high $\mathrm{P}$, As did not clearly change the spectrally resolved kinetics of NPQ_i6, while NPQ_r5 increased at higher As concentrations after two weeks as observed in spatially resolved kinetics (Fig. 5).

\section{Oxygen exchange by photosynthesis and respiration}

To assess the overall impact of hampered photosynthetic parameters on gas exchange, we measured oxygen exchange after four weeks of As treatment. At lower irradiance, a slight $(n=146$, $P=0.967^{\mathrm{NS}}$ ) increase in oxygen release per fresh weight was noticed at sublethal As concentrations in low $\mathrm{P}$ plants. However, at higher irradiances oxygen release decreased at $5 \mu \mathrm{M}$ As $(n=146, P<0.001)$, and, beyond that, measurement was not possible. At high $\mathrm{P}$, no major change in comparison to control was noticed up to $5 \mu \mathrm{M}$ As. Beyond that As concentration, however, oxygen release decreased slightly. Respiration initially increased in both low $\mathrm{P}$ (up to $0.5 \mu \mathrm{M}$ As) and high $\mathrm{P}$ (up to $2 \mu \mathrm{M}$ As), followed by decrease but never to levels lower than that of the control (Fig. S3, ESI $\dagger$ ).

\section{Production of superoxide and peroxides}

To re-investigate As-induced oxidative stress as suggested earlier, ${ }^{17,20}$ we measured superoxide and peroxide production. A concentration and duration dependent increase in the level of superoxide production was observed in both high and low P. However, it started at a later point of time than the changes in pigments and non-photochemical exciton quenching, and it was strong only at lethal As $(n=42, P<0.001)$. The increase in superoxide production at higher As concentrations was much stronger at low $\mathrm{P}$ than at high $\mathrm{P}$ (Fig. 6). Surprisingly, no production of peroxides was measurable under As stress (data not shown), although the same detection method had revealed peroxide production in $\mathrm{Cr} / \mathrm{Cu}$-stressed $E$. gracilis $^{34}$ and in $\mathrm{Cu}$-stressed and $\mathrm{Cd} / \mathrm{Ni}$-stressed $C$. demersum (unpublished data).

\section{Starch accumulation}

To have a second measure apart from growth about the net output of photosynthesis, accumulation of starch in young and old tissues of the plants was measured after four weeks of As treatment (Fig. 7). The level of starch was higher in low $\mathrm{P}$ plants than in high $\mathrm{P}$ plants $(n=42, P<0.001)$, and old tissues 
(a)

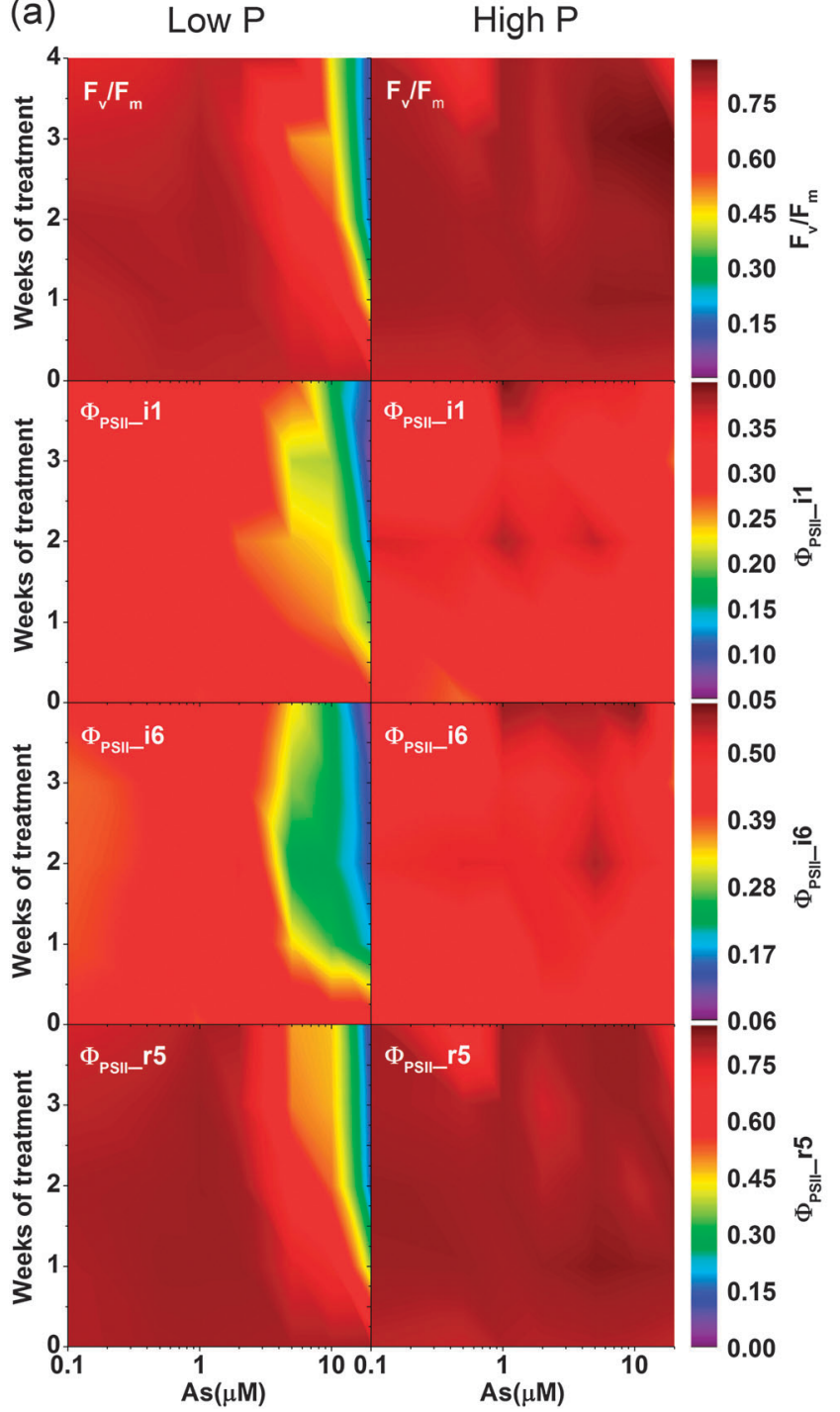

(b)

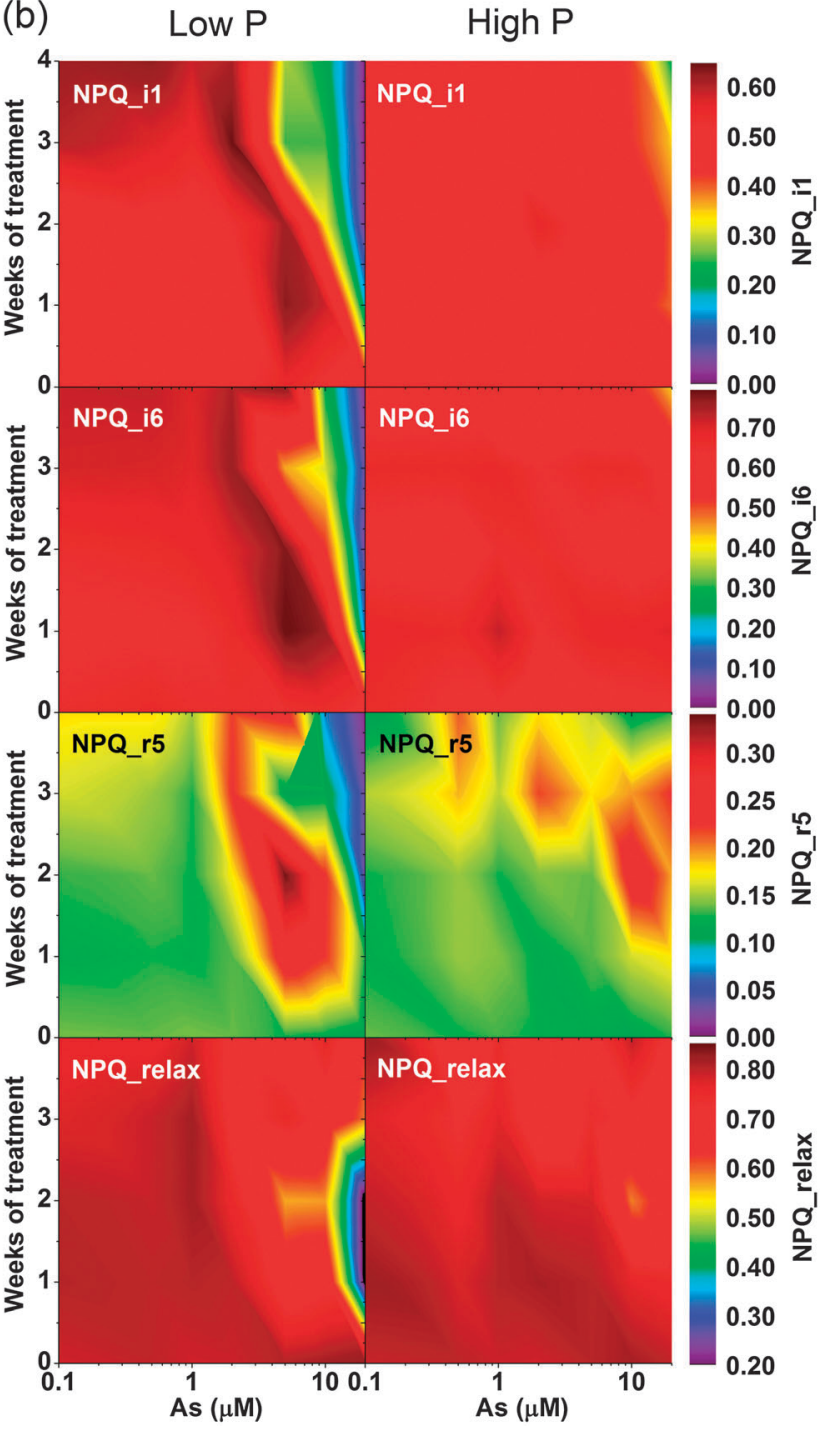

Fig. 4 Effect of As on photosynthesis biophysics measured by in vivo chlorophyll fluorescence kinetic measurements. Plants were exposed to As for four weeks under low and high $\mathrm{P}$ conditions (two-dimensional figure showing the time course on the vertical axis and the As concentration series on the horizontal axis of each panel). The data are the mean of three experiments. (a) Effect on photochemical parameters measured as $F_{\mathrm{v}} / F_{\mathrm{m}}=\left(F_{\mathrm{m}}-F_{\mathrm{o}}\right) / F_{\mathrm{m}}$; the maximal dark-adapted photochemical quantum yield of the photosystem II reaction centre, $\Phi_{\mathrm{PSII}}=\left(F_{\mathrm{m}}{ }^{\prime}-F_{\mathrm{t}}{ }^{\prime}\right) / F_{\mathrm{m}}{ }^{\prime}$; light-acclimated linear electron flow, $\Phi_{\mathrm{PSII}}$ i1 after $10 \mathrm{~s}$ of actinic light, $\Phi_{\mathrm{PSII} \_} \mathrm{i} 6$ after $200 \mathrm{~s}$ of actinic light, $\Phi_{\mathrm{PSII}} \mathrm{r} 5=$ Capacity of electron flow after $200 \mathrm{~s}$ of relaxation in the dark. (b) Effect on non-photochemical quenching of energy measured as $N P Q=\left(F_{m}-F_{m}{ }^{\prime}\right) / F_{m}$, NPQ_i1; after $10 \mathrm{~s}$ of actinic light, NPQ_i6; after 200 s of actinic light, $N P Q_{-} r 5$; non-photochemical energy quenching after 200 s of dark phase. NPQ_relax = (NPQ_i6-NPQ_r5)/NPQ_i6; relaxation of non-photochemical quenching within $200 \mathrm{~s}$ after end of actinic light.

accumulated more starch than young tissues. However, both low and high $\mathrm{P}$ conditions yielded similar trends of starch accumulation, i.e. an initial decrease up to $2 \mu \mathrm{M}$ As followed by a sharp increase up to $20 \mu \mathrm{M}$ As. At low $\mathrm{P}$, there was no young tissue available for the measurement at 10 and $20 \mu \mathrm{M}$ As after four weeks.

\section{Discussion}

The levels of As ( 0.5 to $20 \mu \mathrm{M}$ ) in this study were chosen on the basis of As levels in severely contaminated areas (see Introduction). As the first obvious and important new result of this study, even these low concentrations led to severe inhibition within four weeks, as discussed in mechanistic detail below. Further, under the present experimental conditions, $C$. demersum accumulated several times more As than reported previously. ${ }^{12}$ This confirmed that in natural environments these plants possess high potential of As accumulation as described by Robinson et al. ${ }^{36}$

The levels of phosphate (P) in the present study ( 1 and $10 \mu \mathrm{M})$ were chosen on the basis of performance of plants in preexperiments for optimum growth and also on the basis of levels of $\mathrm{P}$ in natural aquifers. ${ }^{37}$ From the growth rate and morphology, it is obvious that without As the low $\mathrm{P}$ condition was more favourable for $C$. demersum growth. However, when exposed to 
Low $\mathrm{P}$
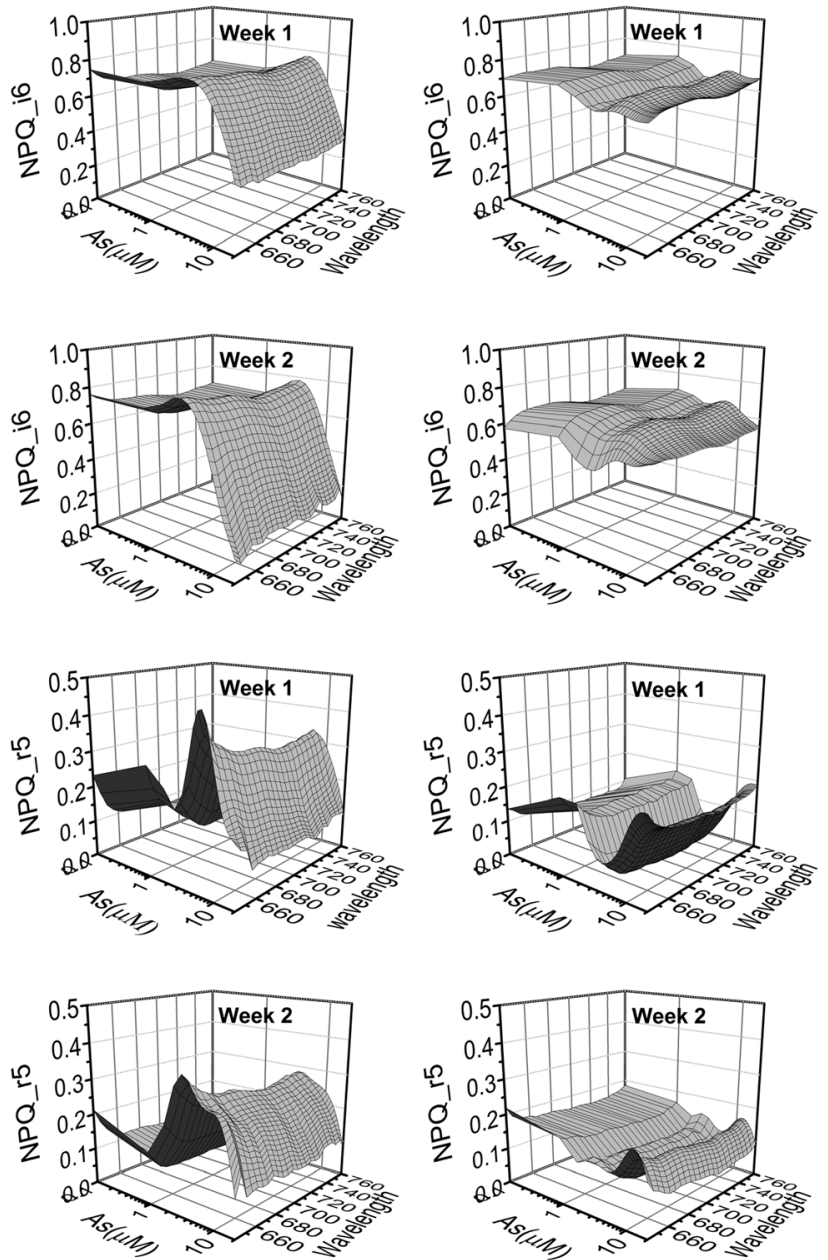

High P
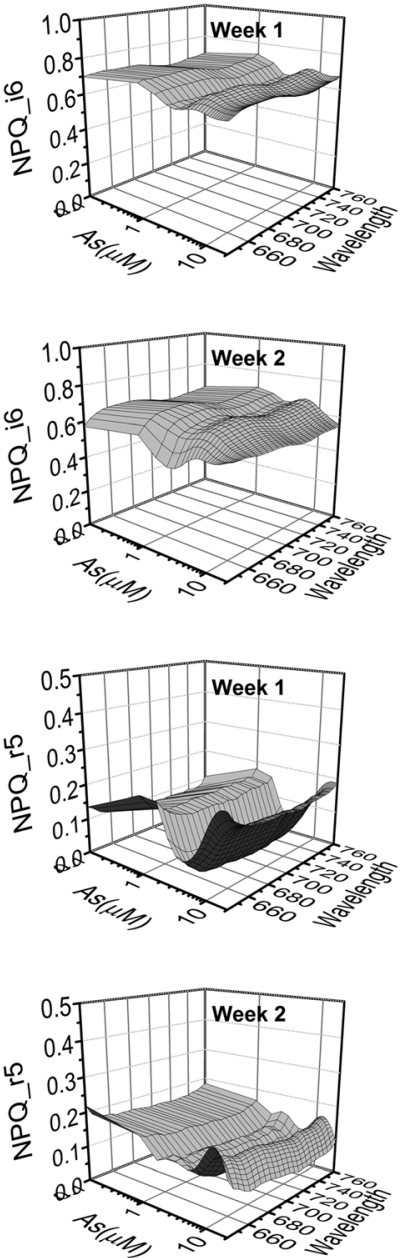

Fig. 5 Effect of As on non-photochemical quenching measured in a spectrally resolved way. Note that the spectra shown are spectra of NPQ = $\left(F_{m}-F_{m}{ }^{\prime}\right) / F_{m}$, not of fluorescence itself; the method of spectrally resolved fluorescence quenching analysis is discussed in detail in Küpper et al. (2007a). Plants were exposed to As under low and high P conditions. Data are the mean of three experiments. NPQ_i6; after 200 s of actinic light, NPQ_r5; after 200 s of dark phase.

As, the low $\mathrm{P}$ plants showed more toxicity than high $\mathrm{P}$ plants. The level of toxicity exerted by $5 \mu \mathrm{M}$ As at low $\mathrm{P}$ was even higher than what occurred at $20 \mu \mathrm{M}$ As at high P. This could be explained by the high accumulation of As at low P. The antagonistic effect of $\mathrm{P}$ on $\mathrm{As}(\mathrm{v})$ uptake had been reported earlier. ${ }^{12,26,38,39}$ However, the concentration of $\mathrm{P}$ taken in these studies was very high in comparison to natural aquifers or in soil solution where it is rarely higher than $10 \mu \mathrm{M}$, i.e. in the high affinity range. ${ }^{37,40}$ Since high affinity $\mathrm{P}$ transporters are the main route of $\mathrm{As}(\mathrm{v})$ uptake, the study of As and P interaction within this range would lead to important conclusions. In the present study, the accumulation of As in plants exposed to $1 \mu \mathrm{M}$ As at low $\mathrm{P}(1 \mu \mathrm{M})$ was 21 -fold higher in young tissues than what occurred at $1 \mu \mathrm{M}$ As in the presence of high $\mathrm{P}(10 \mu \mathrm{M})$. Further, in low $\mathrm{P}$ plants, the strong influx of As, especially at $>1 \mu \mathrm{M}$ As, resulted in severe irreversible toxicity, becoming lethal from $5 \mu \mathrm{M}$ As.

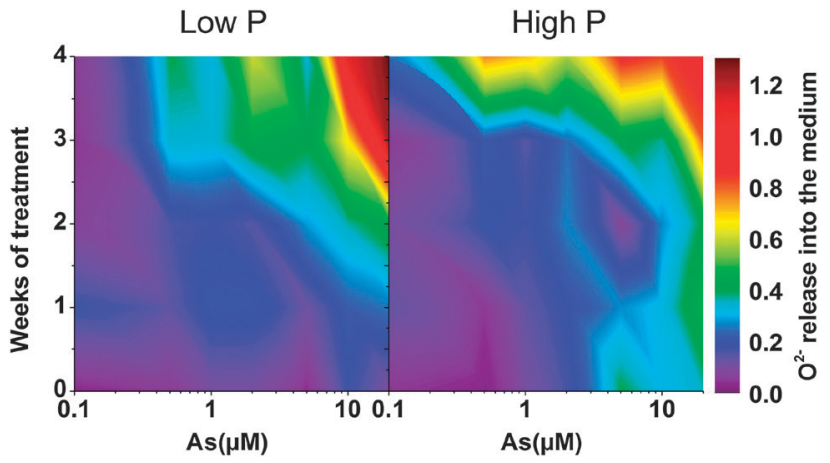

Fig. 6 Effect of As on superoxide generation by leaves. Plants were exposed to As under low and high $\mathrm{P}$ conditions. Data are mean of three experiments (two-dimensional figure showing the time course on the vertical axis and the As concentration series on the horizontal axis).

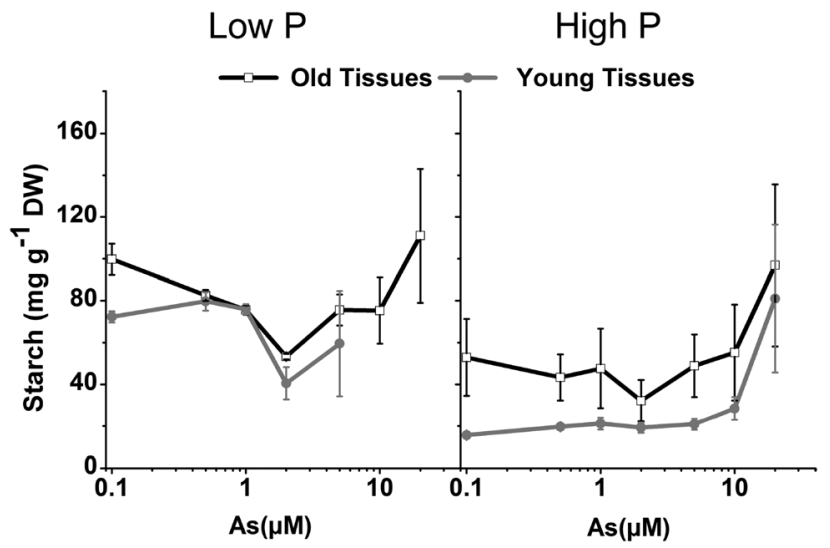

Fig. 7 Effect of As on starch accumulation in young and old tissues. Plants were exposed to As for four weeks under low and high P conditions. Data are mean \pm SE of three experiments.

In contrast, in high $\mathrm{P}$ plants, the As influx was probably slow enough to allow detoxification of most of the As in the cell as reviewed by Meharg and Hartley-Whitaker. ${ }^{9}$ This would explain why the high $\mathrm{P}$ plants acclimated to sublethal As after longer exposure i.e. after $>2$ weeks. It was reported earlier that As inhibits the uptake of $\mathrm{P}$ in plants. ${ }^{38}$ In contrast, in the present study, the low $\mathrm{P}$ plants exhibited a sharp increase in $\mathrm{P}$ accumulation with increase in As concentration. Probably in low P plants the decrease in the molar ratio of $\mathrm{P}$ to As increased intra-cellular competition. This might be sensed by the plants as $\mathrm{P}$ starvation, leading to up-regulation of $\mathrm{P}$ transporters resulting in increased accumulation of $\mathrm{P}$. However, this enhanced activity of $\mathrm{P}$ transporters could further increase As influx. Thus, As and $\mathrm{P}$ seem to affect each other's uptake in a complex way depending on environmental and intracellular concentration. Further, this also indicates that there is a switch in the plants' response to sublethal vs. lethal As, which was also evident from other parameters discussed below. The higher level of $\mathrm{P}$ in young tissues than in old tissues is probably due to the greater requirement for $\mathrm{P}$ by growing tissues. However, despite being taken up through same transporters, As showed a different distribution pattern. 
In high $\mathrm{P}$ plants, a relatively high proportion of total As was found in old tissues, while in low P plants both young and old tissues accumulated an almost similar level of As. This might be attributed to the As detoxification mechanism. The strong positive correlation between As and S in plants in the present study points to the role of thiol containing ligands (viz. glutathione and phytochelatins; PCs) in As detoxification. ${ }^{12,28}$ Since As-thiol complexes are known to be stored in vacuoles, ${ }^{41,42}$ old tissues, having bigger vacuoles and thus more capacity for As storage than young tissues, accumulated more As. In our recent study, we found that the epidermis of mature leaves accumulated more As (mostly bound to PCs) than that of young mature leaves. ${ }^{28}$ However, in low P plants, the allocation of As into old tissues was most likely limited probably due to inadequate transport of As-thiol complexes into the vacuole as a result of rapid influx of As. Inadequate downstream processing of metal-PC complexes has been reported as the limiting step in PC mediated detoxification of cadmium at higher concentrations by $C$. demersum and by transgenic tobacco plants. ${ }^{43,44}$ This may be similar for the metalloid As.

The decrease in the level of chlorophylls upon As exposure was negatively correlated with the accumulation of As. Chlorophylls are the main photosynthetic pigments in plants. Thus, a decrease in the level of chlorophylls will result in decreased photosynthesis under light-limited conditions (e.g. at the bottom of ponds where C. demersum lives) and eventually hamper plant growth. Thus, it is among the most important results of this study that pigments started to decrease even at very low, sublethal As concentrations both under low and high P conditions (Fig. 8). The decrease in chlorophylls may be attributed to their reduced biosynthesis, to an enhanced enzymatic degradation, ${ }^{45,46}$ or to uncontrolled chemical degradation upon cell death. Among the carotenoids analysed, violaxanthin acts as an antenna pigment while antheraxanthin and $\beta$-carotene-like pigments play a protective role through non-photochemical quenching of excess energy, which is particularly important under stress conditions. ${ }^{47,48}$ Lutein takes part both in light harvesting ${ }^{49}$ and non-photochemical quenching of excess energy. ${ }^{47,48}$ Although violaxanthin and $\beta$-carotene-like pigments showed a slight increase, the severe reduction in antheraxanthin + lutein in low $\mathrm{P}$ plants contributed to the impairment of photosynthesis upon As exposure, which ultimately resulted in decreased photosynthetic oxygen release. While in high $\mathrm{P}$ plants antheraxanthin + lutein levels were not affected by As, violaxanthin and $\beta$-carotene-like pigments gradually increased. As a result, only little damage to photosynthetic capacity occurred in high $\mathrm{P}$ plants. The sudden increase in Chl a and $\beta$-carotene-like pigments in old tissues at lethal As in low P plants was likely caused by the epiphytic cyanobacteria which were observed to grow under these conditions and could not be removed completely from the fragile old tissues at these treatments.

Interestingly, non-photochemical quenching (NPQ) increased up to $5 \mu \mathrm{M}$ As at low P and $10 \mu \mathrm{M}$ As at high P, only at even higher (lethal) As it decreased. The relaxation of NPQ was inhibited already at sublethal As concentrations, such that NPQ_r5 in As exposed plants was higher than in the control. The spectrally resolved florescence kinetics of NPQ showed that the enhancement of NPQ had a maximum at shorter wavelengths,

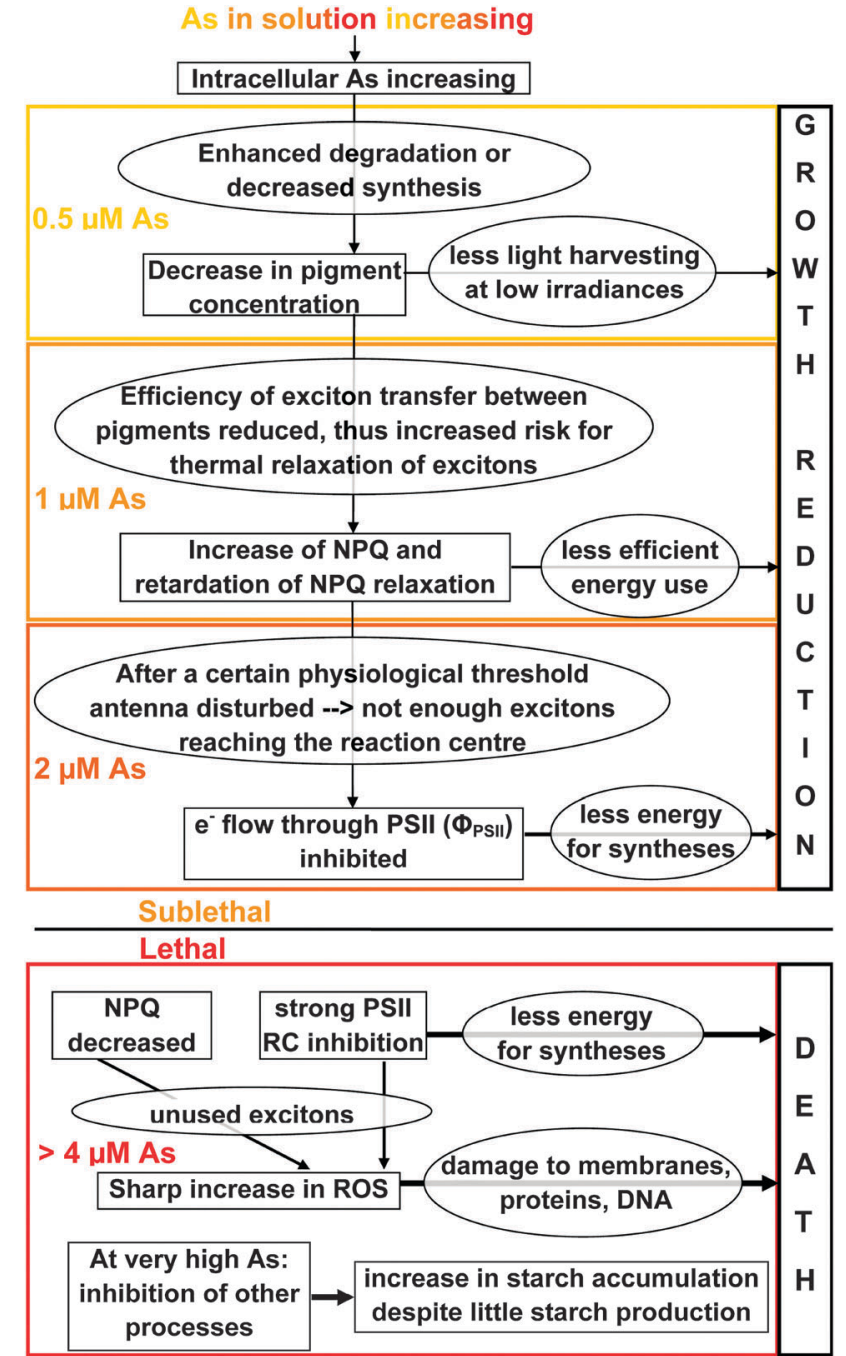

Fig. 8 Scheme of pathways of arsenic toxicity in plants. The scheme was derived from the results of the current study and general knowledge about bioenergetics (the rectangles indicate measured effects, and the ovals are interpretations). The concentration thresholds shown are for low $P$ conditions; at high $P$ they are shifted upwards with lethality being reached at $>20 \mu \mathrm{M}$.

where mostly the outer PSII antenna (light harvesting complex II, LHCII) emits fluorescence. Thus the enhancement of NPQ in the actinic light phase of the measurement (NPQ_i6) and the slower relaxation in the dark (elevated NPQ_r5) indicate a change of the coupling of LHCII that enhanced LHCIImediated non-photochemical energy dissipation. The elevated, slowly relaxing NPQ is at first glance surprising in view of the decreased energy input into the reaction centres caused by the decrease in pigments. This change in NPQ regulation could be a consequence, however, of less coupling of the remaining pigments. This diminished coupling would lead to more damage if the energy that cannot be transferred to the reaction centres would be transferred e.g. to singlet oxygen (Fig. 8). The inhibition of electron flow $\left(\Phi_{\mathrm{PSII}}\right)$ started at a later point of time and at higher As concentrations, forming the transition to the lethal effects of As. 
At lethal As concentrations under low $\mathrm{P}$ conditions, all photosynthetic parameters strongly decreased. Not only was the electron flow through PSII hampered, but also NPQ stopped functioning. This resulted in a completely non-functional photosynthetic system as evident by the saturation parameter, which reached almost zero at these concentrations. In high $\mathrm{P}$ plants, even at the lethal concentration (20 $\mu \mathrm{M}$ As) maximal photochemical efficiency of the PSIIRC decreased only slightly, and electron flow through PSII did not significantly change even at this time. This means that the few remaining photosystems still had functional electron transport chains. Non-photochemical quenching (NPQ) decreased at lethal concentrations at high $\mathrm{P}$, with more decrease in the initial part of the actinic light phase (NPQ_i1) than at the end (NPQ_i6), and also NPQ relaxation was inhibited. Inhibition of controlled non-photochemical dissipation of excess excitons means that these excitons can e.g. excite oxygen. Thus, the inhibition of NPQ at lethal As most likely led to the strong increase in superoxide in dying plants. Earlier studies suggested that oxidative stress plays a decisive role in As toxicity. ${ }^{17,20}$ Interestingly, in our study the oxidative stress was not a reason for reduced growth or inhibition of photosynthesis, as it appeared later and at higher As concentrations than inhibition of NPQ and retardation in growth. Instead, its late onset shows that it is clearly a result of malfunctioning photosynthesis (Fig. 8). In contrast to other toxic treatments, As toxicity did not lead to measurable production of peroxides that are detectable using the well-known ROS detection agent $\mathrm{H}_{2}$ DCFDA.

The rate of respiration increased up to sub-lethal concentrations and then decreased at lethal concentrations in comparison to controls in both low and high $\mathrm{P}$ plants. These changes were stronger at low $\mathrm{P}$ than at high $\mathrm{P}$, but the low vs. high $\mathrm{P}$ difference was less than for photosynthesis, showing that the drastically stronger toxicity at low $\mathrm{P}$ is not related to changes in respiration. The higher accumulation of starch in old tissues than in young tissues might be a food storage strategy of the plant. However, the initial decrease in the level of starch up to $2 \mu \mathrm{M}$ As followed by an increase up to lethal concentrations appears to be related to the differential stress perception response of the plants at lethal and sub-lethal concentrations of As. It seems that initially plants tried to defend themselves against As toxicity by some mechanism such as increased synthesis of detoxification-related amino acids and other metabolites, which induced catabolic processes, e.g. respiration and induced utilization of starch. However, at higher As concentrations, starch utilization became inhibited. Further, the toxicity experienced by the plants could directly be related to the change in the distribution pattern of As from sublethal to lethal concentrations, i.e. increase in the level of As in the mesophyll at lethal As concentration, as observed in our recent study. ${ }^{28}$

In conclusion, with the increase in intracellular As, plants induced detoxification processes such as enhanced acquisition of S, probably to synthesize thiol containing ligands to complex As. Nevertheless, intracellular weakly bound As increased, initiating a decline in photosynthetic pigments, leading to moderate growth inhibition through decreased light harvesting. However, until a certain physiological threshold, the core photosynthesis
( $\mathrm{e}^{-}$transport and PSIIRC) was not affected. Up to this threshold, other key physiological processes, i.e. gas exchange through photosynthesis and respiration, were also not affected. However, a further increase in intracellular As disrupted $\mathrm{e}^{-}$flow through PSII and later inhibited PSIIRC. This malfunctioning of photosynthesis led to enhanced generation of superoxide and eventually the appearance of severe toxic symptoms.

The different sequence of events in arsenic-induced damage as revealed now suggests that for breeding As-resistant plants focus should be on different aspects of metabolism than previously believed (more on photosynthesis, less on oxidative stress). Although in higher plants the root acts as barrier for As translocation to the shoot, still a significant amount of As accumulates in shoots causing growth inhibition and lower yield, e.g. in rice. Thus the mechanism of shoot toxicity revealed in the present study is equally important for crops and other plants having roots. Increasing $\mathrm{P}$ concentration in the nutrient solution drastically shifted the threshold of lethal As effects. This did not only involve reducing As influx through uptake competition, but also involved altering uptake regulation and modifying intracellular processes. The latter was evident from the constant threshold As concentration of the onset of pigment effects compared to the shifted threshold concentration of PSIIRC inhibition and death.

\section{Acknowledgements}

The authors are thankful to Peter Kroneck for critical reading of the manuscript. This work was supported by the Alexander von Humboldt Foundation (Alexander von Humboldt Fellowship to S.M.), the German Research Foundation (DFG; grant KU 1495/8), University of Konstanz and the Helmholtz Centre for Environmental Research (UFZ), Leipzig.

\section{Notes and references}

1 U. K. Chowdhury, B. K. Biswas, T. R. Chowdhury, G. Samanta, B. K. Mandal, G. C. Basu, C. R. Chanda, D. Lodh, K. C. Saha, S. K. Mukherjee, S. Roy, S. Kabir, Q. Quamruzzaman and D. Chakraborti, Environ. Health Perspect., 2000, 108, 393-397.

2 P. L. Smedley and D. G. Kinniburgh, Appl. Geochem., 2002, 17, 517-568.

3 H. Brammer and P. Ravenscroft, Environ. Int., 2009, 35, 647-654.

4 F. J. Zhao, S. P. McGrath and A. A. Meharg, Annu. Rev. Plant Biol., 2010, 61, 535-559.

5 R. D. Tripathi, S. Srivastava, S. Mishra, N. Singh, R. Tuli, D. K. Gupta and F. J. Maathuis, Trends Biotechnol., 2007, 25, 158-165.

6 C. J. Asher and P. F. Reay, Aust. J. Plant Physiol., 1979, 6, 459-466.

7 S. V. Isayenkov and F. J. M. Maathuis, FEBS Lett., 2008, 582, 1625-1628.

8 J. F. Ma, N. Yamaji, N. Mitani, X. Y. Xu, Y. H. Su, S. P. McGrath and F. J. Zhao, Proc. Natl. Acad. Sci. U. S. A., 2008, 105, 9931-9935. 
9 A. A. Meharg and J. Hartley-Whitaker, New Phytol., 2002, 154, 29-43.

10 A. Raab, J. Feldmann and A. A. Meharg, Plant Physiol., 2004, 134, 1113-1122.

11 P. M. Bleeker, H. W. J. Hakvoort, M. Bliek, E. Souer and H. Schat, Plant J., 2006, 45, 917-929.

12 S. Mishra, S. Srivastava, R. D. Tripathi and P. K. Trivedi, Aquat. Toxicol., 2008, 86, 205-215.

13 S. Mishra, S. Srivastava, S. Dwivedi and R. D. Tripathi, Environ. Toxicol., 2013, 28, 419-430.

14 B. K. Mandal and K. T. Suzuki, Talanta, 2002, 58, 201-235.

15 A. A. Carbonell-Barrachina, F. Burló, A. Burgos-Hernández, E. López and J. Mataix, Sci. Hortic., 1997, 71, 167-176.

16 X. Liu, S. Zhang, X. Shan and Y. G. Zhu, Chemosphere, 2005, 61, 293-301.

17 J. Hartley-Whitaker, G. Ainsworth and A. A. Meharg, Plant, Cell Environ., 2001, 24, 713-722.

18 S. Srivastava, S. Mishra, R. D. Tripathi, S. Dwivedi, P. K. Trivedi and P. K. Tandon, Environ. Sci. Technol., 2007, 41, 2930-2936.

19 P. V. Mylona, A. N. Polidoros and J. G. Scandalios, Free Radicals Biol. Med., 1998, 25, 576-585.

20 R. Requejo and M. Tena, Phytochemistry, 2005, 66, 1519-1528.

21 N. Singh, L. Q. Ma, M. Srivastava and B. Rathinasabapathi, Plant Sci., 2006, 170, 274-282.

22 M. Shri, S. Kumar, D. Chakrabarty, P. K. Trivedi, S. Mallick, P. Misra, D. Shukla, S. Mishra, S. Srivastava, R. D. Tripathi and R. Tuli, Ecotoxicol. Environ. Saf., 2009, 72, 1102-1110.

23 R. Rai, S. Pandey and S. P. Rai, Ecotoxicology, 2011, 20, 1900-1913.

24 G. Sánchez-Viveros, R. Ferrera-Cerrato and A. Alarcón, Water, Air, Soil Pollut., 2011, 217, 455-462.

25 W. W. Wenzel, A. Brandstetter, H. Wutte, E. Lombi, T. Prohaska, G. Stingeder and D. C. Adriano, J. Plant Nutr. Soil Sci., 2002, 165, 221-228.

26 M. J. Abedin, J. Feldmann and A. A. Meharg, Plant Physiol., 2002, 128, 1120-1128.

27 P. Xue, C. Yan, G. Sun and Z. Luo, Environ. Sci. Pollut. Res., 2012, 19, 3969-3976.

28 S. Mishra, G. Wellenreuther, J. Mattusch, H.-J. Stärk and H. Küpper, Plant Physiol., 2013, 163, 1396-1408.

29 V. Blüm, E. Stretzke and K. Kreuzberg, Acta Astronaut., 1994, 33, 167-177.
30 F. Zhao, S. P. McGrath and A. R. Crosland, Commun. Soil Sci. Plant Anal., 1994, 25, 407-418.

31 H. Küpper, S. Seibert and A. Parameswaran, Anal. Chem., 2007, 79, 7611-7627.

32 H. Küpper, A. Parameswaran, B. Leitenmaier, M. Trtilek and I. Setlik, New Phytol., 2007, 175, 655-674.

33 E. Andresen, J. Lohscheider, E. Setlikova, I. Adamska, M. Simek and H. Küpper, New Phytol., 2010, 185, 173-188.

34 I. Rocchetta and H. Küpper, New Phytol., 2009, 182, 405-420.

35 X. Y. Xu, S. P. McGrath and F. J. Zhao, New Phytol., 2007, 176, 590-599.

36 B. Robinson, N. Kim, M. Marchetti, C. Moni and L. Schroeter, Environ. Exp. Bot., 2006, 58, 206-215.

37 R. G. Wetzel, Limnology. Lake and River Ecosystems, Academic Press, San Diego, CA, edn 3, 2001.

38 A. A. Meharg and M. R. Macnair, New Phytol., 1990, 116, 29-35.

39 A. A. Meharg and M. R. Macnair, J. Exp. Bot., 1992, 43, 519-524. 40 R. L. Bieleski, Annu. Rev. Plant Physiol., 1973, 24, 225-252.

41 W. Y Song, J. Park, D. G. Mendoza-Cózatl, M. SuterGrotemeyer, D. Shim, S. Hörtensteiner, M. Geisler, B. Weder, P. A. Rea, D. Rentsch, J. I. Schroeder, Y. Lee and E. Martinoia, Proc. Natl. Acad. Sci. U. S. A., 2010, 107, 21187-21192.

42 K. L. Moore, M. Schröder, Z. Wu, B. G. H. Martin, C. R. Hawes, S. P. McGrath, M. J. Hawkesford, J. F. Ma, F. L. Zhao and C. R. Grovenor, Plant Physiol., 2011, 156, 913-924.

43 S. Mishra, R. D. Tripathi, S. Srivastava, S. Dwivedi, P. K. Trivedi, O. P. Dhankher and A. Khare, Bioresour. Technol., 2009, 100, 2155-2161.

44 S. Wojas, S. Clemens, J. Hennig, A. Skłodowska, E. Kopera, H. Schat, W. Bal and D. M. Antosiewicz, J. Exp. Bot., 2008, 59, 2205-2219.

45 M. Jain and R. Gadre, Water, Air, Soil Pollut., 1997, 93, 109-115. 46 M. Jain and R. Gadre, J. Plant Physiol., 2004, 161, 251-255.

47 K. K. Niyogi, O. Bjorkman and A. R. Grossman, Proc. Natl. Acad. Sci. U. S. A., 1998, 94, 14162-14167.

48 P. Müller, X. Li and K. K. Niyogi, Plant Physiol., 2001, 125, 1558-1566.

49 C. C. Gradinaru, I. H. M. van Stokkum, A. A. Pascal, R. van Grondelle and H. van Amerongen, J. Phys. Chem. B, 2000, 104, 9330-9342. 